\title{
BMJ Open Quality of life among individuals with rugby-related spinal cord injuries in South Africa: a descriptive cross- sectional study
}

\author{
Marelise Badenhorst, ${ }^{1,2}$ James Craig Brown, ${ }^{1,2}$ Mike I Lambert, ${ }^{1,2}$ \\ Willem Van Mechelen, ${ }^{1,2,3,4}$ Evert Verhagen ${ }^{1,2,5}$
}

To cite: Badenhorst M, Brown JC, Lambert MI, et al. Quality of life among individuals with rugby-related spinal cord injuries in South Africa: a descriptive crosssectional study. BMJ Open 2018;8:e020890. doi:10.1136/ bmjopen-2017-020890

\section{- Prepublication history for} this paper is available online. To view these files, please visit the journal online (http://dx.doi. org/10.1136/bmjopen-2017020890).

Received 30 November 2017 Revised 10 April 2018 Accepted 6 June 2018
Check for updates

(C) Author(s) (or their employer(s)) 2018. Re-use permitted under CC BY-NC. No commercial re-use. See rights and permissions. Published by BMJ.

For numbered affiliations see end of article.

Correspondence to

Dr Evert Verhagen;

e.verhagen@vumc.nl

\section{ABSTRACT}

Objectives Rugby-related spinal cord injuries (SCls) are rare but life altering and traumatic events. Little is known about the long-term consequences and outcomes of players who have sustained these injuries. This study investigated current quality of life (QoL) and factors associated with QoL, among individuals with rugby-related $\mathrm{SCl}$ in South Africa, by using the International Classification of Functioning, Disability and Health (ICF) framework. Design Descriptive cross-sectional study.

Setting Rugby-related SCl population of South Africa, as captured in the BokSmart/Chris Burger Petro Jackson Players' Fund database.

Participants Ninety $(n=90)$ of the 102 eligible players on the database agreed to participate in the study.

Main outcome measure The relationship between QoL, as measured with the WHO Quality of Life questionnaire (WHOQOL-BREF) and specific independent variables (demographic information, level of independence and participation in various activities and life roles) was investigated. Variables that were significantly associated with QoL in bivariate analyses were included in multiple linear regression analyses.

Results The mean score and SD of the WHOQOL-BREF was $15.1 \pm 2.3$ arbitrary units. Participation (an ICF framework construct) and income were significantly associated with overall QoL $(p<0.001)$. Participation was the only variable significantly associated with all QoL subdomains $(p<0.001)$. Additionally, number of health concerns, type of healthcare (public vs private) and level of education were significantly associated with various $\mathrm{QoL}$ domains $(p<0.001)$.

Conclusions On average, these individuals with rugbyrelated SCI presented with higher QoL scores than other comparable SCl studies. However, lower levels of participation and income, certain levels of education, increased health concerns and use of public healthcare were associated with lower levels of QoL. Sporting bodies have a responsibility to optimise player welfare, by acting on the modifiable factors associated with QoL.

\section{INTRODUCTION}

Sport plays a role in the aetiology of spinal cord injury (SCI) in various countries. ${ }^{1}$ Rugby union, specifically, is a popular team
Strengths and limitations of this study

- This study addresses the paucity of knowledge of the long-term consequences of catastrophic sporting injuries.

- The results from this study is a first step in describing specific factors associated with quality of life (QoL) in rugby players who sustain spinal cord injury (SCls). Future studies should further investigate the relationships identified in this study.

- Based on criticisms of existing objective participation measures, this study used a participation measure that assesses participation limitations that are meaningful and important to the individual (subjective experience).

- Although some of the modifiable factors in this study may be South African specific, concepts such as participation may be important for all individuals with SCl.

- This study considered only certain variables and their association with QoL, while other factors, such as coping strategies, self-esteem and athletic identity, may also contribute to QoL.

sport, characterised by frequent exposure to physical contact and high-impact collisions. $^{2}$ Compared with other sports, rugby has been identified as one of the individual sports with highest risk for SCI. ${ }^{3}$ Though the actual risk is low, serious and potentially disabling injuries are associated with the sport. ${ }^{4}$ In 2009, a nationwide injury prevention programme, 'BokSmart', was launched in South Africa in conjunction with the Chris Burger Petro Jackson Players' Fund (CBPJPF) to reduce these catastrophic injuries. ${ }^{5}$ The CBPJPF is a non-profit organisation that provides support for rugby players who have sustained a catastrophic injury. ${ }^{5}$ Although catastrophic injuries such as SCIs are rare, the outcome remains a life-altering event for the player and their family. ${ }^{4}$ In South Africa, the overall annual incidence rate for permanent 
Health Condition

(disorder or disease)

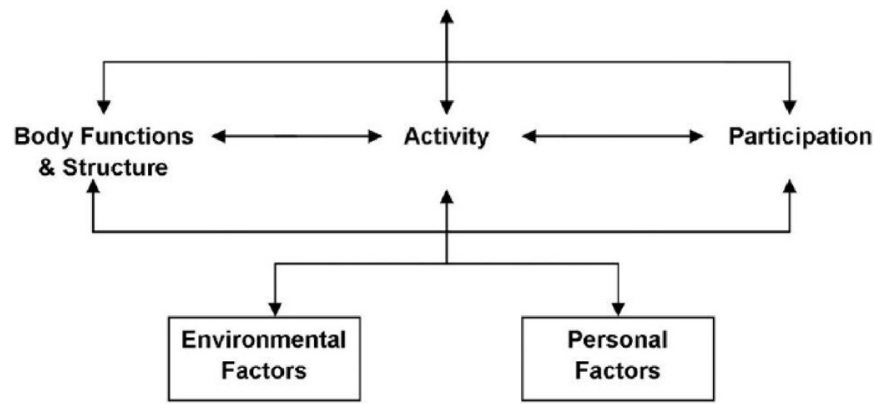

Figure 1 The International Classification of Functioning, Disability and Health from WHO (2001).

outcome SCIs between 2008 and 2014 were reported as 1.8 injuries per 100000 players (95\% CI 0.3 to 3.4$){ }^{6}$

The consequences of such an injury can be assessed by the WHO's International Classification of Functioning, Disability and Health (ICF). ${ }^{7}$ The ICF contains three components of human functioning: (1) body functions and structures (physiological, psychological and anatomical functions), (2) activity (execution of tasks) and (3) participation (involvement in life situations). Disability, in this context, refers to the interaction of impairments in body structure and function, limitations of activity (difficulties an individual may have in executing tasks or activities) and restrictions in participation (problems an individual may experience in involvement in life situations) (figure 1). Instead of focusing on the physical injury as the main determinant of functional outcome, the framework considers the influence of other factors, such as personal factors and the individual's environment. ${ }^{7}$

A concept not incorporated in the ICF is quality of life (QoL). ${ }^{8}$ The WHO defines QoL as an individual's perception of their position in life in the context of their culture, value systems, standards and concerns. Subsequently, a conceptual revision of the ICF diagram (the ICF-CR) has been proposed to enhance its biopsychosocial content by depicting QoL as the largest component of human functioning, with contributions of each of the other subsystems. ${ }^{8}$ The incorporation of QoL allows the impact of any given health condition, its effect on daily life and the experience from the personal perspective of those affected to be appreciated more comprehensively. ${ }^{89}$ Measuring QoL after SCI is important, as the purpose of SCI rehabilitation includes functional recovery and independence, community reintegration and ongoing enhancement of QoL. ${ }^{10}$ QoL has been found to be diminished following SCI and may be affected by personal factors, such as sociodemographic and psychological factors, or cultural factors such as race and ethnicity. ${ }^{11-13}$ QoL may also be affected by economic and environmental factors, such as accessibility to healthcare, quality of education, adequacy of housing and opportunities for employment. ${ }^{11} 14$ Specifically, paid employment and time since injury has previously emerged as important cross-cultural predictors of
QoL after SCI. ${ }^{15}$ Additionally, participation in home, social and leisure activities have been shown to have a positive effect on QoL. ${ }^{15} 16$

SCI has been described as one of the most devastating neurological impairments an individual can face, with profound effects on both the injured person and their family. ${ }^{17}$ Qualitative studies of the experiences of people who have suffered an SCI through playing rugby have shown that the lives of these individuals can change from being highly active and positive to being severely restrictive and unfavourable for their psychological and social health. ${ }^{18} 19$ International sporting federations have an obligation to protect the health of their athletes. ${ }^{20}$ As is evident from the various injury prevention programmes in rugby, ${ }^{5}$ prevention of serious spinal injury seems to be a key priority, but less attention is given to the consequences for players who sustain SCIs playing rugby. To our knowledge, no studies have investigated factors associated with QoL in individuals who have sustained rugby-related or other sports-related SCIs. Identification of these barriers and facilitators to optimal QoL is an essential first step in establishing strategies to enhance QoL. Therefore, the aim of this study was to investigate current QoL and factors associated with QoL, among individuals with rugby-related SCI, by using the ICF framework.

\section{METHODS}

\section{Participants and data collection}

The entire group of rugby players who had sustained rugby-related SCIs in South Africa $(n=113)$ formed the population of this study. The group included players of all age groups and level of proficiency (amateur to professional). Access to this population was obtained through the CBPJPF/BokSmart database. ${ }^{5}$ The database is managed jointly by the BokSmart programme and the CBPJPF. According to BokSmart's Serious Injury Protocol and reporting process, all potentially disabling of life-threatening head, neck or spine injuries, sustained by any player at any level of rugby union, is reported to the Serious Injury Case Manager (SICM) of the CBPJPF who makes key decisions regarding the injured player's management. The SICM records the final diagnosis on the database 1 month after injury during a follow-up visit or consultation with the medical doctor in charge of the case. Though it is possible that some catastrophic injuries may not have been reported, the potential benefit of financial, logistical and psychological support that is associated with reporting rugby-related injuries in South Africa should reduce this possibility. Players were eligible to participate in the study if they were 18 years or older and spoke either Afrikaans or English. Additionally, players were only eligible if at least 1 year had elapsed since their injury to minimise possible psychological burden. ${ }^{21}$ Eligible players $(n=102)$ were contacted telephonically and invited to participate in the study. Players who agreed to participate and provided informed consent were included in the study $(\mathrm{n}=90)$. Data collection visits were 
conducted at their homes or places of work throughout South Africa. Data collection consisted of two parts: the collection of questionnaire data for this study, followed by semi-structured interviews investigating the long-term consequences of SCI in this population. Questionnaires were completed individually by participants with sufficient writing ability. The researcher assisted with completion of questionnaires for participants who were unable to write. ${ }^{22}$

\section{Patient and public involvement}

The research objectives and study design of this study was formulated in consultation with a person with an SCI, who is also the CEO of QuadPara Association of South Africa (QASA), and with the CBPJPF. Persons with SCIs were not further involved in the recruitment or conduction of the study. Study findings will be disseminated to both QASA and the CBPJPF. Findings will also be summarised in a plain language report. This report will be sent to the participants by email, post or discussed via telephone, depending on their preference.

\section{Dependent variable}

QoL was assessed using the abbreviated version of the WHO Quality of Life questionnaire (WHOQOL-BREF). The WHOQOL-BREF is a cross-culturally valid questionnaire that consists of 26 items within four QoL domains: physical health, psychological health, social relationships and environment. ${ }^{22}{ }^{23}$ Higher scores indicate greater perceived QoL in that domain. The psychometric soundness of the use of WHOQOL-BREF in a SCI population has been confirmed, and it has been described as the most established instrument to assess QoL after SCI. ${ }^{24}{ }^{25}$ The frequency distribution of the four domains of the WHOQOL-BREF was found to be nearly symmetric and showed no floor or ceiling effects. All domains showed good internal consistency (Cronbach's $\alpha=0.74-0.78$ ), with the exception of the social relationships domain $(\alpha=0.54)$. It has been noted that the social relationships domain calculation is based only on three items, whereas those for the other domains are based on 6-8 items, thus affecting the alpha value. ${ }^{25}$ The WHOQOL-BREF was also shown to correlate in appropriate domains with other QoL measures such as the 36-Item Short Form Health Survey (SF-36) $\left(r_{s}=0.33-0.78\right){ }^{24}$

According to scoring guidelines, each domain's score was calculated by multiplying the mean score by 4 to make domain scores comparable with the scores in the WHOQOL-100. ${ }^{22}$ The score for each domain therefore ranges from 4 to 20. The overall QoL score was obtained by summing the mean score of each domain. ${ }^{26}$ The overall score ranges from 4 to 20 and higher scores indicate greater perceived overall QoL. The procedure for missing values described by the WHOQOL-BREF scoring guidelines was applied in one case. The guideline stipulates that where an item is missing, the mean of other items in the domain is substituted, provided no more than two items are missing from the domain and with the exception of domain 3, where the domain should only be calculated if $<1$ item is missing. ${ }^{22}$ The case had complete data after this substitution and was retained in the analysis.

\section{Independent variables}

Demographic data

Personal information collected included age, marital status, education level, employment status, income and time since injury. Environmental factors included the residing province, type of transport most often relied on and type of healthcare accessed (public, private or both). An asset indicator approach was used to determine a proxy of socioeconomic status (SES) by formulating a composite score from the presence of assets such as electricity, indoor flushing toilet, indoor running water, television, satellite dish, computer, internet, motor vehicle, refrigerator, microwave, washing machine, radio and method of cooking. ${ }^{27}$ The asset indicator scores were used to divide the sample into low, middle and high socioeconomic groups based on percentile cut-off points. ${ }^{27}$

\section{Impairment, activity and participation measures}

Impairment was measured by three variables, injury level, completeness of SCI and the presence of health concerns or complications such as pressure ulcers, spasticity, contractures, urinary tract infections, bowel problems, blood pressure problems and pain. The number of health concerns indicated by the participant were summed and presented as a numeric value. The injury level was obtained from the records of the SICM of the CBPJPF and confirmed during interviews with the participants. For the purpose of this investigation, injury level was categorised based on functional capabilities into high quadriplegia (C3-C4, using chin-controlled wheelchairs), low quadriplegia (C5-C8, using hand-controlled or manual wheelchairs), paraplegia and ambulant quadriplegia.

Activity/level of independence was measured with the third version of the Spinal Cord Independence Measure (SCIM). The SCIM is a widely used instrument designed to measure functioning in activities of daily living in persons with SCI. ${ }^{28}$ The SCIM has 19 daily tasks grouped into three subscales. Item scores are weighted according to their clinical relevance and are graded according to difficulty. Each item has between 2 and 9 grades, and the total SCIM score ranges from 0 to 100 . Higher scores indicate greater levels of independence. The subscales assess the areas of self-care, respiration and sphincter management and mobility. The SCIM has been shown to be valid and reliable in multicentre studies. ${ }^{28}$

The inclusion of participation in disability studies is important, but the subjective nature of participation can cause challenges with measurement. ${ }^{29}{ }^{30}$ The Craig Handicap Assessment and Reporting technique (CHART) is one of the most widely used measure of participation in research. ${ }^{31}$ However, CHART is classified as an activity-focused, objective measure of participation (outsider's perspective) and is based on the International 
Classification of Impairment, Disability and Handicap (ICIDH) framework, which is an outdated version of the ICF. ${ }^{32}$ The ICF's focus on difficulty of participation reflects the outsider's view of what is important and has been criticised for not including subjective aspects of participation.$^{32}$ Issues of choice and control, importance, belonging and satisfaction have been included in recent definitions of participation. ${ }^{33} 34$ The value of participation is evident in life situations that are meaningful and important to the individual (subjective experience), as opposed to factors of participation that are considered important by the healthcare professional or researcher. ${ }^{30}$ Based on these criticisms of existing objective participation measures, a relatively new concept and measure of participation was used. ${ }^{30}$ Participation enfranchisement assesses the subjective experience of participation and is a reflection of the meaning that individual's attach to participation across life domains. ${ }^{35}$ Enfranchisement is defined as active engagement, choice and control, access and opportunity, fulfilling responsibilities, having an impact and supporting others and social connection. ${ }^{35}$ This construct is a reflection of the individual's perception of the communities in which they want to participate and the extent to which their communities are perceived to be valuing, respecting and inclusive. ${ }^{35}$ Enfranchisement can also reflect personal factors, such as cultural background and SES, as well as environmental factors, such as varying opportunities between rural and urban communities. ${ }^{35}$ Heinemann et a $\hat{l}^{85}$ developed the Community Participation Indicators (CPIs), which consists of separate components to measure participation enfranchisement. Importance of participation, which consists of 13 items (eg, 'I do important things with my life'), and control over participation, which consists of 14 items (eg, 'I participate in activities that I choose'). Rasch analyses of the two item sets from a diverse disability sample demonstrated adequate internal validity (person separation $=2.66$ and 2.28; item separation $=15.50$ and 14.81 for importance of participation and control over participation, respectively). ${ }^{35}$ Residual principle components analyses have suggested that the two item sets are one dimensional. The two enfranchisement measures share $44 \%$ of their variance. ${ }^{35}$ The CPI has previously been used to measure participation in a SCI population. ${ }^{36}$

\section{Statistics}

Descriptive statistics for sociodemographic and lesion-related variables were performed. Apart from the usual scoring of the WHOQOL-BREF, the five items of the WHOQOL-BREF (WHOQOL-5) that cover overall QoL, satisfaction with health, daily activities, relationships and living conditions were also calculated separately. This allowed for comparison with WHOQOL-BREF data from the only other SCI QoL study that could be found for South Africa. ${ }^{15}$ All independent variables presented in table 1 and table 2 were included in the bivariate analyses to assess their association with the dependent variables (total QoL and the four QoL domains). Participation,
Table 1 Sociodemographic and lesion-related variables of participants $(n=90)$

\begin{tabular}{lcccc}
\hline Quantitative variables & Mean & SD & Min & Max \\
\hline Age & & & & \\
Current age & 40 & 11 & 18 & 68 \\
Years since injury & 8 & 10 & 1 & 48 \\
Age when injured & 22 & 6 & 14 & 40 \\
\hline \multicolumn{2}{l}{ Number of health concerns } & 4 & 1 & 10 \\
\hline Categorical variables & N & $\%$ & & \\
\hline
\end{tabular}

Race

$\begin{array}{lll}\text { African } & 15 & 17 \\ \text { Mixed ancestry } & 28 & 31 \\ \text { Caucasian } & 47 & 52\end{array}$

Marital status

$\begin{array}{lll}\text { Unmarried } & 62 & 69 \\ \text { Married } & 21 & 23\end{array}$

$\begin{array}{lll}\text { Divorced } & 6 & 7 \\ \text { Separated } & 1 & 1\end{array}$

Province

$\begin{array}{lrr}\text { Eastern cape } & 20 & 2 \\ \text { Free state } & 2 & 2 \\ \text { Gauteng } & 12 & 13\end{array}$

\begin{tabular}{lrr|} 
Kwazulu-Natal & 5 & 6 \\
Limpopo & 1 & 1 \\
Mpumalanga & 2 & 2 \\
Northern cape & 3 & 3 \\
Northwest & 5 & 6 \\
Western cape & 40 & 44
\end{tabular}

$\begin{array}{lrr}\text { Level of injury } & & \\ \text { High quadriplegia: (C3-C4) } & 7 & 8 \\ \text { Low quadriplegia: (C5- C8) } & 71 & 79 \\ \text { Paraplegia } & 1 & 1 \\ \text { Ambulant quadriplegia } & 11 & 12\end{array}$

Completeness of injury

$\begin{array}{lrr}\text { Complete } & 37 & 41 \\ \text { Incomplete } & 53 & 59 \\ \text { Current employment } & & \\ \text { Unemployed } & 37 & 41 \\ \text { Employed } & 43 & 48 \\ \text { Student } & 8 & 9 \\ \text { Correctional services } & 2 & 2\end{array}$

Education

\begin{tabular}{lcc} 
Primary level & 7 & 8 \\
$\begin{array}{l}\text { Secondary (high school not } \\
\text { completed) }\end{array}$ & 30 & 33 \\
$\begin{array}{l}\text { Secondary (high school } \\
\text { completed) }\end{array}$ & 23 & 26 \\
Tertiary level & 30 & 33 \\
\hline
\end{tabular}

Continued 


\begin{tabular}{|c|c|c|}
\hline Categorical variables & $\mathbf{N}$ & $\%$ \\
\hline \multicolumn{3}{|l|}{ Income $^{*}$} \\
\hline Very low (R1-R2500) & 33 & 37 \\
\hline Low (R2501-R8000) & 20 & 22 \\
\hline Medium (R8001-R20000) & 14 & 16 \\
\hline High (more than R20000) & 14 & 16 \\
\hline Not provided/missing data & 9 & 10 \\
\hline \multicolumn{3}{|l|}{ Asset indicator score (SES) } \\
\hline Low SES & 32 & 36 \\
\hline Medium SES & 17 & 19 \\
\hline High SES & 41 & 46 \\
\hline \multicolumn{3}{|l|}{ Type of residence } \\
\hline Care facility: dependent & 12 & 13 \\
\hline Care facility: independent & 2 & 2 \\
\hline Private house & 65 & 72 \\
\hline Block of apartments & 3 & 3 \\
\hline $\begin{array}{l}\text { Wendy house/room in back } \\
\text { yard }\end{array}$ & 4 & 4 \\
\hline Town house & 2 & 2 \\
\hline Correctional services & 2 & 2 \\
\hline \multicolumn{3}{|l|}{ Transport } \\
\hline Has own transport & 48 & 53 \\
\hline $\begin{array}{l}\text { Relies on others/paid } \\
\text { transport }\end{array}$ & 32 & 36 \\
\hline $\begin{array}{l}\text { Relies on care facility } \\
\text { transport }\end{array}$ & 10 & 11 \\
\hline \multicolumn{3}{|l|}{ Type of healthcare } \\
\hline Public healthcare & 42 & 47 \\
\hline Private healthcare & 37 & 41 \\
\hline Both & 11 & 12 \\
\hline \multicolumn{3}{|l|}{ Exercise $^{*}$} \\
\hline None & 39 & 43 \\
\hline 1-4 times/week & 17 & 19 \\
\hline More than five times/week & 33 & 37 \\
\hline Missing data & 1 & 1 \\
\hline
\end{tabular}

*Variable with missing data.

SES, socioeconomic status.

number of health concerns, current age, age when injured, years since injury and level of independence were treated as quantitative variables. The remaining variables were treated as categorical variables. The categories of each categorical variable are presented in table 1 and was coded as such for analysis. Variables that were significantly associated with QoL were included in the multiple regression analysis to examine the factors related to overall QoL. The same procedure was performed for each of the four QoL domains. Akaike information criterion (AIC) was used to find the most parsimonious model of overall QoL as well as each QoL domain. ${ }^{37} \mathrm{~A}$ p value of $\leq 0.05$ was considered statistically significant for all independent variables. During analysis, listwise exclusion of cases with missing values was applied. ${ }^{37}$ Thus, if a participant had a missing value for any variable, then the whole case was excluded from any analysis that included that variable. The assumption of independence of errors were met for all models. The models exhibited no influential cases, no multicollinearity and no heteroscedasticity, and the residuals were normally distributed.

\section{RESULTS}

Ninety $(n=90)$ of the 102 , eligible rugby-related SCIs in the CBPJPF database were included in the study after they had agreed to participate. The participants were all male. Injuries were sustained over the period of 19682015. Twenty-nine $(32 \%)$ of the injuries had occurred at school level, $56(62 \%)$ at club/senior level, $3(3 \%)$ within correctional services and $2(2 \%)$ were social rugby-related (social game). Forty-one injuries were sustained in the scrum (46\%), $33(37 \%)$ in the tackle, 12 in the ruck $(13 \%)$ and the remaining $4(4 \%)$ in other phases of play. Table 1 presents the general characteristics of the sample. The participant's ages ranged from 18 to 68 years, with a mean age of 40 years. The majority of the participants were unmarried $(69 \%)$. The mean time since injury was 18 years, with a minimum time of 1 year.

The study population included $11 \quad(\mathrm{n}=11)$ SCIs who presented with permanent neurological deficits but who could walk (ambulant quadriplegia), either with assistance, crutches or ankle-foot prostheses. One-way analysis of variance revealed no significant differences between the mean QoL scores of the high quadriplegic and low quadriplegic $(\mathrm{p}=0.68)$, high quadriplegic and ambulant quadriplegic $(p=0.23)$ or low quadriplegic and ambulant quadriplegic groups $(p=0.33)$. The ambulant quadriplegia group was therefore retained in the sample for the full analysis. Thirty-seven $(41 \%)$ of the sample was unemployed, and subsequently the highest percentage of the sample $(37 \%)$ had a very low monthly income (R1-R2500). Thirty-seven $(41 \%)$ of the participants had not completed high school. According to the asset indicator score, $36 \%$ was grouped into low SES and $46 \%$ into high SES. Forty-seven per cent made use of public healthcare, $41 \%$ of private and $11 \%$ of both. Table 2 presents the questionnaire scores of the sample. The mean

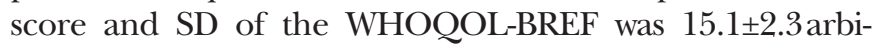
trary units (AU). The domain scores ranged from 14.6 $\mathrm{AU}$ to $16.1 \mathrm{AU}$.

Variables that showed an association with one or more of the dependent variables in the bivariate analyses are presented in table 3. Variables that showed no association with any of dependent variables were omitted from this table. Independent variables that were significantly associated with outcomes of the WHOQOL-BREF were included in the multiple regression (table 4 ). In the final model, participation: control (B: 0.09 ; 95\% CI 0.07 to $0.12)$, very low income $(\mathrm{B}:-1.65 ; 95 \% \mathrm{CI}-2.70$ to -0.60$)$ and low income (B: $-1.45 ; 95 \% \mathrm{CI}-2.60$ to -0.30$)$ were 
Table 2 Quality of life (QoL), level of independence and participation scores

\begin{tabular}{|c|c|c|c|c|c|c|}
\hline & Mean & Median & SD & Minimum & Maximum & IQR \\
\hline \multicolumn{7}{|l|}{ QoL } \\
\hline Total QoL (out of 20$)^{\star}$ & 15.1 & 14.8 & 2.3 & 7.9 & 19.8 & 3.3 \\
\hline \multicolumn{7}{|l|}{ Missing data: $n=3$} \\
\hline \multicolumn{7}{|l|}{ Physical domain* } \\
\hline 4-20 transformation & 14.7 & 14.3 & 2.6 & 9.7 & 20.0 & 4.6 \\
\hline 0-100 transformation & 66.9 & 64.3 & 16.5 & 36 & 100 & 29 \\
\hline \multicolumn{7}{|l|}{ Missing data: $n=1$} \\
\hline \multicolumn{7}{|l|}{ Psychological domain* } \\
\hline 4-20 transformation & 16.1 & 16.7 & 2.6 & 7.3 & 20.0 & 3.3 \\
\hline 0-100 transformation & 75.6 & 79.2 & 16.4 & 21 & 100 & 21 \\
\hline \multicolumn{7}{|l|}{ Missing data: $n=1$} \\
\hline \multicolumn{7}{|l|}{ Social domain* } \\
\hline 4-20 transformation & 14.6 & 14.7 & 3.2 & 5.3 & 20.0 & 4.0 \\
\hline 0-100 transformation & 66.0 & 66.7 & 20.2 & 8 & 100 & 25 \\
\hline \multicolumn{7}{|l|}{ Missing data $n=3$} \\
\hline \multicolumn{7}{|l|}{ Environmental domain* } \\
\hline 4-20 transformation & 14.9 & 15.0 & 3.0 & 6.5 & 20.0 & 4.5 \\
\hline 0-100 transformation & 68.4 & 68.8 & 18.9 & 16 & 100 & 28 \\
\hline \multicolumn{7}{|l|}{ Missing data $n=3$} \\
\hline WHOQOL-5* & 19.7 & 20.0 & 2.8 & 13.0 & 25.0 & 4.0 \\
\hline \multicolumn{7}{|l|}{ Missing data $n=3$} \\
\hline \multicolumn{7}{|l|}{ Participation* } \\
\hline CPI: importance & 57.1 & 54.7 & 11.9 & 29.6 & 100.0 & 15.8 \\
\hline CPI: control & 67.3 & 63.6 & 15.6 & 37.1 & 100.0 & 20.5 \\
\hline \multicolumn{7}{|l|}{ Missing data $n=3$} \\
\hline \multicolumn{7}{|l|}{ Level of independence } \\
\hline SCIM & 34.8 & 24.0 & 23.2 & 3.0 & 97.0 & 23.0 \\
\hline
\end{tabular}

*Variable with missing data.

CPI, Community Participation Indicator; SCIM, Spinal Cord Independence Measure; WHOQOL-5, 5-item World Health Organisation Quality of Life questionnaire

most strongly associated with overall QoL (table 4). This model explained $50 \%$ of the variance in $\mathrm{QoL}(\mathrm{F}=18.2$, $\mathrm{p}<0.001)$. For the physical health domain, participation: control (B: $0.07 ; 95 \%$ CI 0.03 to 0.10 ), very low income (B: $-2.47 ; 95 \%$ CI -3.89 to -1.04$)$, low income (B: -2.25 ; $95 \% \mathrm{CI}-3.79$ to -0.71$)$ and number of health concerns (B: $-0.34 ; 95 \%$ CI -0.59 to -0.09 ) were significantly associated with QoL. The model explained $38 \%$ of the variance in physical health QoL $(\mathrm{F}=9.0, \mathrm{p}<0.001)$. Participation: control (B: $0.08 ; 95 \%$ CI 0.04 to 0.12 ) and participation: importance (B: $0.05 ; 95 \%$ CI -0.00 to -0.10 ) were the only variables included in the final model of the psychological domain, explaining $39 \%$ of the variance $(\mathrm{F}=27.8$, $\mathrm{p}<0.001)$. This was also the case for the social domain where participation: control (B: $0.08 ; 95 \%$ CI 0.03 to 0.13 ) and participation: importance (B: $0.07 ; 95 \%$ CI 0.00 to 0.13 ) explained $32 \%$ of the variance in this domain $(\mathrm{F}=19.7, \quad \mathrm{p}<0.001)$. Participation: control (B: 0.08;
95\% CI 0.05 to 0.11 ) and the use of private healthcare (B: 2.66; 95\% CI 1.36 to 3.86), or both private and public healthcare (B: 2.61; $95 \%$ CI 0.94 to 4.37 ) compared with public healthcare only were positively associated with increased environmental QoL. Uncompleted secondary level schooling (B: $-2.47 ; 95 \%$ CI -4.61 to -0.33 ) and completed secondary level schooling (B: -3.02; $95 \%$ CI -5.34 to -0.69 ) was negatively associated with environmental QoL $(\mathrm{F}=16.6, \mathrm{p}<0.001)$.

Participation's strong association within all the regression models prompted further exploration of this variable. All variables were again assessed in a bivariate analysis with participation as the dependent variable. Three variables showed associations with participation: control at $\mathrm{p}<0.01$ level. These variables were level of independence $(r=0.376, \mathrm{p}<0.001)$, number of health concerns $(r=0.306, \mathrm{p}=0.004)$ and exercise frequency $(r=0.321, \mathrm{p}=0.002)$. 
Table 3 Bivariate analysis: association between dependent and independent variables (analysis of variance and Spearman's correlation)

\begin{tabular}{|c|c|c|c|c|c|}
\hline & Total QoL & Physical QoL & $\begin{array}{l}\text { Psychological } \\
\text { QoL* }\end{array}$ & Social QoL* & $\begin{array}{l}\text { Environmental } \\
\text { QoL }\end{array}$ \\
\hline \multicolumn{6}{|l|}{ Quantitative variables } \\
\hline CPI: importance & $r=0.518 ; p<0.001$ & $r=0.259 ; p=0.02$ & $r_{s}=0.558 ; p<0.001$ & $r_{s}=0.535 ; p<0.001^{*}$ & $r=0.360 ; p=0.001$ \\
\hline SCIM & $r=0.292 ; p=0.01$ & $r=0.281 ; p=0.01$ & $r_{\mathrm{s}}=0.185 ; \mathrm{p}=0.08$ & $x$ & $x$ \\
\hline \multicolumn{6}{|l|}{ Categorical variables } \\
\hline Province & $x$ & $x$ & $x$ & $x$ & $P=0.001$ \\
\hline $\begin{array}{l}\text { Injury level functional } \\
\text { level }\end{array}$ & $\times$ & $\times$ & $\times$ & $x$ & $\times$ \\
\hline $\begin{array}{l}\text { Asset indicator score } \\
\text { (SES) }\end{array}$ & $x$ & $x$ & $x$ & $x$ & $\mathrm{P}<0.001$ \\
\hline Transport & $x$ & $x$ & $x$ & $x$ & $P<0.001$ \\
\hline Type of healthcare & $P=0.03$ & $x$ & $x$ & $x$ & $P<0.001$ \\
\hline Exercise & $\times$ & $P=0.04$ & $x$ & $x$ & $x$ \\
\hline
\end{tabular}

$r=$ Pearson's correlation coefficient.

$r_{\mathrm{s}}=$ Spearman's correlation coefficient.

${ }^{*}$ Psychological and Social domains not normally distributed.

ANOVA, analysis of variance; CPI, Community Participation Indicator; QoL, quality of life; SCIM, Spinal Cord Independence Measure; SES,

socioeconomic status.

\section{DISCUSSION}

This study investigated the QoL and the factors associated with QoL in individuals with rugby-related SCIs. It has previously been reported that people with disabilities in South Africa have lower QoL than people without. ${ }^{38}$ The current sample had higher QoL scores compared with the only WHOQOL-BREF score data that could be found for a South African SCI population. ${ }^{15}$ This sample scored higher, in all four domains, than a comparable study in a Taiwanese SCI population. ${ }^{26}$ Except for the environmental domain, this sample also scored higher than an Australian study sample. ${ }^{16}$ Instead, these QoL scores were similar to those reported for healthy adults. ${ }^{39}$ These comparisons are limited to studies that used the WHOQOL-BREF or WHOQOL-100. Nonetheless, the present study population appears to possess unique characteristics potentially affecting their QoL. Further research is needed to explain this finding, but possible influencing factors may include the population type (active individuals with a similar mechanism of injury) and the assistance provided to these injured players by a dedicated organisation (CBPJPF).

The findings of the study indicated that participation and income were significantly associated with overall QoL. In addition to these two factors, the number of health concerns, type of healthcare and level of education were significantly associated with the various QoL domains. Previous research has indicated that participation in home, work, social and community activities was highly related to QoL. ${ }^{16}{ }^{40}$ Importantly, participation was the only ICF component that was significantly associated with all QoL domains in this study. Similarly, the Taiwanese study found participation to be consistently associated with all domains of the WHOQOL-BREF. ${ }^{26}$ The significant relationship of participation with QoL reiterates its importance as a modifiable factor for individuals with SCI. To improve the participation of persons with SCI, it is important to understand how potentially modifiable factors, such as exercise, are associated with participation in this population. Physical activity has been shown to be associated with better QoL in healthy adults as well as persons with SCIs. ${ }^{41}{ }^{42}$ Additionally, reviews have proposed that sports and recreational activities improve self-confidence and performance of activities of daily life in people with SCI. ${ }^{43}$ Compared with non-active persons with disabilities, those who engage in organised sports have decreased depression and anxiety and increased opportunities for employment. ${ }^{44}$ In this study, exercise was not directly related to QoL in the final regression models. However, it was indirectly related to QoL through its association with participation. The importance of exercise in this sample of previously active rugby players before their injury may be far reaching. Individuals 
Table 4 Multiple regression models for quality of life (QoL)

\begin{tabular}{|c|c|c|c|c|c|c|c|c|}
\hline \multirow[b]{2}{*}{ Model } & \multirow[b]{2}{*}{$\mathbf{R}$} & \multirow[b]{2}{*}{$\mathbf{R}^{2}$} & \multirow[b]{2}{*}{ Adjusted $\mathrm{R}^{2}$} & \multirow[b]{2}{*}{$\begin{array}{l}\text { Independent } \\
\text { variables }\end{array}$} & \multirow{2}{*}{$\begin{array}{l}\text { Unstandardised } \\
\text { coefficients } \\
\text { B }\end{array}$} & \multicolumn{2}{|c|}{$95 \% \mathrm{Cl}$} & \multirow[b]{2}{*}{$P$ values } \\
\hline & & & & & & $\begin{array}{l}\text { Lower } \\
\text { bound }\end{array}$ & $\begin{array}{l}\text { Upper } \\
\text { bound }\end{array}$ & \\
\hline \multirow[t]{6}{*}{ Overall QoL } & 0.70 & 0.50 & 0.47 & $\begin{array}{l}\text { Participation: } \\
\text { control }\end{array}$ & 0.09 & 0.07 & 0.12 & $<0.001$ \\
\hline & & & & Income & & & & \\
\hline & & & & Very low income & -1.65 & -2.70 & -0.60 & 0.001 \\
\hline & & & & Low income & -1.45 & -2.60 & -0.30 & 0.02 \\
\hline & & & & Medium income & -0.52 & -1.77 & 0.74 & 0.42 \\
\hline & & & & High income & Base variable & & & \\
\hline \multirow[t]{7}{*}{ Physical domain } & 0.62 & 0.38 & 0.34 & $\begin{array}{l}\text { Participation: } \\
\text { control }\end{array}$ & 0.07 & 0.03 & 0.10 & $<0.001$ \\
\hline & & & & Income & & & & \\
\hline & & & & Very low income & -2.47 & -3.89 & -1.04 & 0.001 \\
\hline & & & & Low income & -2.25 & -3.79 & -0.71 & 0.01 \\
\hline & & & & Medium income & -1.21 & -2.88 & 0.47 & 0.16 \\
\hline & & & & High income & Base variable & & & \\
\hline & & & & Health concerns & -0.34 & -0.59 & -0.09 & 0.01 \\
\hline \multirow[t]{2}{*}{$\begin{array}{l}\text { Psychological } \\
\text { domain }\end{array}$} & 0.63 & 0.40 & 0.38 & $\begin{array}{l}\text { Participation: } \\
\text { control }\end{array}$ & 0.08 & 0.04 & 0.12 & $<0.001$ \\
\hline & & & & $\begin{array}{l}\text { Participation: } \\
\text { importance }\end{array}$ & 0.05 & -0.00 & 0.10 & 0.05 \\
\hline \multirow[t]{2}{*}{ Social domain } & 0.57 & 0.32 & 0.30 & $\begin{array}{l}\text { Participation: } \\
\text { control }\end{array}$ & 0.08 & 0.03 & 0.13 & 0.002 \\
\hline & & & & $\begin{array}{l}\text { Participation: } \\
\text { importance }\end{array}$ & 0.07 & 0.00 & 0.13 & 0.04 \\
\hline \multirow[t]{10}{*}{$\begin{array}{l}\text { Environmental } \\
\text { domain }\end{array}$} & 0.71 & 0.51 & 0.47 & $\begin{array}{l}\text { Participation: } \\
\text { control }\end{array}$ & 0.08 & 0.05 & 0.11 & $<0.001$ \\
\hline & & & & Education & & & & \\
\hline & & & & $\begin{array}{l}\text { Secondary level: } \\
\text { uncompleted }\end{array}$ & -2.47 & -4.61 & -0.33 & 0.03 \\
\hline & & & & $\begin{array}{l}\text { Secondary level: } \\
\text { completed }\end{array}$ & -3.02 & -5.34 & -0.69 & 0.01 \\
\hline & & & & Tertiary level & -1.12 & -3.47 & 1.23 & 0.355 \\
\hline & & & & Primary level & Base variable & & & \\
\hline & & & & Healthcare & & & & \\
\hline & & & & Private & 2.66 & 1.36 & 3.86 & $<0.001$ \\
\hline & & & & $\begin{array}{l}\text { Combination: } \\
\text { private and public }\end{array}$ & 2.61 & 0.94 & 4.37 & 0.003 \\
\hline & & & & Public & Base variable & & & \\
\hline
\end{tabular}

who identify as athletes are more likely to maintain, or find the need to maintain, sporting behaviour over the long term. ${ }^{45}$ Qualitative research has examined the experiences of people who have suffered a SCI through playing sport. ${ }^{18194647}$ These studies have revealed that individuals with strong athletic identity before the SCI can have adaptation difficulties after their injury. ${ }^{19}$ However, athletic identity has also been reported as factor that can promote recovery and is considered as a means to enhance longterm adjustment to disability. ${ }^{48}$ This may be explained by research that has shown athletic identity to be a predictor of sport participation among individuals with acquired physical disabilities. ${ }^{49}$ Sports participation has also been associated with improved QoL. ${ }^{42}$ Certain barriers may impede exercise or sporting behaviour, such as cost, level of disability, health complications, lack of facilities, difficulties with transport and accessibility. ${ }^{50}$ It is important to overcome as many of these barriers as possible, as exercise participation may be an essential component of the player's identity. ${ }^{49}$ This requires an in-depth individualised 


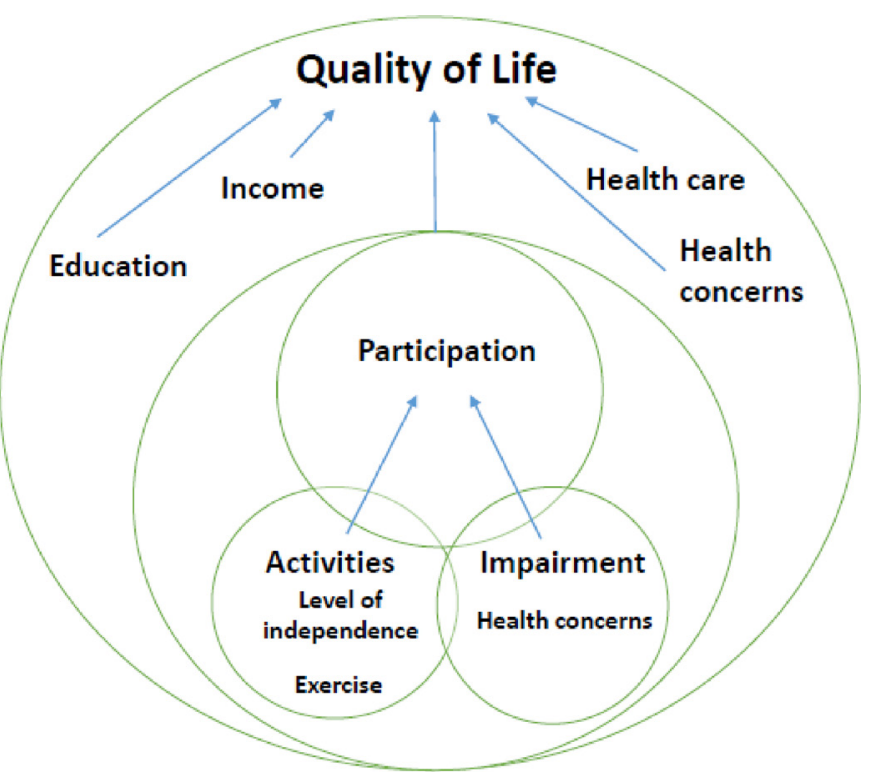

Figure 2 Factors associated with QoL based on the ICF-CR framework (based on Ravenek et $a l^{8}$ ). QoL, quality of life.

assessment to understand the specific participation components that are perceived as important to the individual. ${ }^{51}$

Among the other components of the ICF, the only impairment variable that was significant in the final model was the number of health concerns. This agrees with other studies that found lower QoL in persons with SCI reporting secondary health problems. ${ }^{52} 53$ Health concerns and complications are important areas of focus for interventions as apart from affecting QoL, these issues may also increase healthcare costs due to rehospitalisations. Furthermore, health concerns in SCI population might create greater barriers to employment, thereby affecting both income and participation in general. ${ }^{54}$ In contrast, level of injury was not associated with QoL in any of the final models. This finding is also consistent with other literature that showed that impairments do not affect QoL directly but rather via their impact on activities and participation. ${ }^{1516}$ In the present study, activity (ie, level of independence) was also not directly related to QoL. It was, however, indirectly related to QoL through its association with participation (figure 2). For a person sustaining an SCI, most self-care activities and wheelchair mobility tasks require specific skills development to reach higher levels of functioning. ${ }^{55}$ An improvement of these skills is likely to have a substantial impact on level of independence. ${ }^{55}$ In South Africa, rehabilitation services are inaccessible to the majority of people as they are concentrated at tertiary institutions or provided by private service providers. ${ }^{5657}$ This could mean that those with an SCI in rural areas of South Africa are less likely to receive specialised rehabilitation, which may inevitably affect their independence. ${ }^{56}$ The findings of a South African household survey confirmed that poor, uninsured, black Africans and rural groups still have inequitable access to healthcare. ${ }^{58}$ These disparities are particularly evident when considering that the poorest quintile of South
Africans receives less than $10 \%$ of the country's health benefits despite requiring close to $40 \%$ of these services. ${ }^{59}$ Disability further impedes accessibility to healthcare. ${ }^{56} 60$ The associations of the type of healthcare being used with QoL may be specific to the nuances of the South African healthcare system. Results from this study indicate that private healthcare, or at least a combination of public and private healthcare, was associated with increased QoL. It is most likely that based on these health inequities, additional external support is necessary for those individuals living with an SCI. In effect, support from the CBPJPF for individuals with rugby-related SCIs, is likely to distinguish them from other SCIs in South Africa.

Owing to difficulties in the quantification of SES in South Africa, we considered many different proxies of SES. ${ }^{27}$ The asset indicator score was not significantly associated in any of the final models, and it is possible that other variables, such as income and education, were better proxies of SES in this sample. Low income was negatively associated with QoL. Sufficient income of either the patient or the household is crucial when considering the life-time cost, care and equipment needs of SCI. A 10-year longitudinal study reported that people with SCI with lower household income had experienced more dissatisfaction, worsening health problems and environmental barriers compared with persons with higher income. ${ }^{61}$ Marginalisation of people with disabilities may result in loss of productivity and opportunities to generate income, which again is linked to health and QoL. ${ }^{62}$ Apart from the monetary gain from employment, this activity would also improve participation, which our study has shown to be associated with QoL. Indeed, productive work has been described as among the most important 'participation activities' for adults with disabilities and being employed is regarded as a key indicator to social integration. ${ }^{1563}$ Unfortunately, the South African Census of 2011 showed low overall absorption rates of people with disability in the labour market. ${ }^{64}$ Apart from employment opportunities, lack of skills and education are also important barriers to successful employment for people with disabilities in South Africa. ${ }^{64}$

The highest level of education attained by participants showed specific associations in the environmental domain. Compared with primary level education, secondary level education was associated with significantly lower environmental QoL scores, while tertiary education was not. This finding is difficult to interpret, as it would have been expected that QoL would increase as the level of education increases. It is possible that the level of education before sustaining the injury may have been low and not necessarily due to the injury. As is the case with healthcare, South Africa still bears the burden of an unequal education system and the children of poor parents attend, for the most part, low-quality schools with high dropout rates. ${ }^{65}$ This limits learners' opportunities for tertiary education and subsequently restricts them to low-level jobs. ${ }^{66}$ Moreover, for a player injured while studying or at school, continuation of their education 
postinjury can be challenging in a country with inequitable access to education and even more so for persons with disabilities. ${ }^{65}$ Another possible explanation is based on the country's political past and Calman's definition of QoL as the gap between expectation and experience. ${ }^{967}$ Calman's theory argues that when faced with a new experience, if the experience matches expectation, there would be no significant decrease in QoL. The environmental QoL of participants with low levels (primary level) of education may have not been influenced to an extent that resulted in further loss of environmental QoL, while for participants with higher than primary level education and possibly higher expectations, this balance was potentially not maintained postinjury.

\section{LIMITATIONS}

Although all participants were fluent in either English or Afrikaans, some nuances of the WHOQOL-BREF and CPI measures may have been lost for participants whose first language was neither Afrikaans nor English. Other factors relating to adjustment and mental health after SCI, such as coping strategies and psychological resources, were not investigated in this study but may explain the remaining variance in the regression models. Furthermore, this study comprised a special population of previously active individuals who acquired a disability playing their sport. It is possible that this 'athletic identity' contributes to the perception of QoL and may thus not be representative of the general SCI population. Further investigation in this regard is warranted. Due to the cross-sectional study design, we were unable to identify factors predicting QoL but could only show associations between the investigated variables. Our study was exploratory and the first study in a South African SCI population to investigate factors associated with QoL. Statistical methods such as path analysis or directed acyclic graphs may be used in future studies in this population to further investigate the relationships identified in this study.

\section{CONCLUSION}

This is the first study to present QoL data for rugby players who have sustained SCIs. On average, this group mostly had higher QoL scores than other comparable SCI studies in non-sporting populations. This could be a consequence of the support given by a dedicated organisation or due to the identity of the group as active rugby players before their injuries. Sporting bodies have a responsibility to optimise player welfare by acting on the modifiable factors associated with reduced QoL, following a sport-related injury. The study indicated that persons with lower levels of participation and income, certain levels of education, increased health concerns and those who make use of public healthcare experienced low levels of QoL. It follows that these individuals may benefit most from tailored and specific interventions. Assisting in strategies to create alternative forms of financial self-sufficiency may be one such opportunity where sporting bodies could show their support. Furthermore, the strong association between participation and QoL in this study emphasises the need to measure this concept in those with SCIs. Although some of the modifiable factors in this study (such as type of healthcare) may be South African specific, concepts such as participation may be important for all individuals with SCI. Studies of a qualitative nature could provide further understanding of the factors associated with QoL.

\section{Author affiliations}

${ }^{1}$ Division of Exercise Science and Sports Medicine, Department of Human Biology, University of Cape Town, Cape Town, Western Cape, South Africa

${ }^{2}$ Amsterdam Collaboration on Health and Safety in Sports, Department of Public and Occupational Health and Amsterdam Public Health Research Institute, VU University Medical Center, Amsterdam, The Netherlands

${ }^{3}$ School of Human Movement and Nutrition Sciences, Faculty of Health and Behavioural Sciences, University of Queensland, Brisbane, Queensland, Australia ${ }^{4}$ School of Public Health, Physiotherapy and Population Sciences, University College Dublin, Dublin, Ireland

${ }^{5}$ Australian Centre for Research into Injury in Sport and its Prevention (ACRISP), Federation University Australia, Ballarat, Australia

Acknowledgements The authors would like to thank the Chris Burger Petro Jackson Players' Fund (CBPJPF) and QuadPara A ssociation of South Africa for their input in formulating the research objectives and the CBPJPF and BokSmart for granting access to participants of this study.

Contributors MB conducted the data collection and was involved in conceptualising the manuscript; she also conducted statistical analyses and wrote the initial drafts of the manuscript. EV and JCB were involved in the statistical analyses and interpretation of the results. All authors were involved in conceptualising and editing drafts of the manuscript.

Funding MB's PhD is funded by the Vrije Universiteit Amsterdam/National Research Foundation (NRF) South Africa Desmond Tutu Doctoral Scholarship, administered through South Africa Vrije Universiteit Strategic Alliances (SAVUSA), the Oppenheimer Memorial Trust and Zuid-Afrikahuis Study foundation for South African students.

Competing interests None declared.

Patient consent Not required.

Ethics approval Ethical clearance for the study was obtained from the University of Cape Town Human Research Ethics Committee (HREC REF: 893/2015).

Provenance and peer review Not commissioned; externally peer reviewed.

Data sharing statement All data are published, and therefore there is no additional data available. Owing to the sensitive nature of the information and appropriate medical ethics, access to the raw data set will be reviewed on request.

Open access This is an open access article distributed in accordance with the Creative Commons Attribution Non Commercial (CC BY-NC 4.0) license, which permits others to distribute, remix, adapt, build upon this work non-commercially, and license their derivative works on different terms, provided the original work is properly cited, appropriate credit is given, any changes made indicated, and the use is non-commercial. See:@http://creativecommons.org/licenses/by-nc/4.0/.

\section{REFERENCES}

1. Lee BB, Cripps RA, Fitzharris M, et al. The global map for traumatic spinal cord injury epidemiology: update 2011, global incidence rate. Spinal Cord 2014;52:110-6.

2. Patricios J. BokSmart - South African rugby's national rugby safety and injury prevention program. Curr Sports Med Rep 2014;13:142-4.

3. Chan CW, Eng JJ, Tator $\mathrm{CH}$, et al. Epidemiology of sport-related spinal cord injuries: A systematic review. J Spinal Cord Med 2016;39:255-64.

4. Fuller CW. Catastrophic Injury in Rugby Union. Sports Medicine 2008;38:975-86. 
5. Viljoen W, Patricios J. BokSmart - implementing a National Rugby Safety Programme. Br J Sports Med 2012;46:692-3.

6. Badenhorst M, Verhagen E, van Mechelen W, et al. A comparison of catastrophic injury incidence rates by Provincial Rugby Union in South Africa. J Sci Med Sport 2017;20:643-7.

7. WHO - World Health Organisation. International Classification of Functioning, Disability and Health. Geneva, 2001. http://www.who. int/classifications/icf/en/.

8. Ravenek MJ, Skarakis-Doyle E, Spaulding SJ, et al. Enhancing the conceptual clarity and utility of the international classification of functioning, disability \& health: the potential of a new graphic representation. Disabil Rehabil 2013;35:1015-25.

9. Carr AJ, et al. Measuring quality of life: Is quality of life determined by expectations or experience? BMJ 2001;322:1240-3.

10. Wood-Dauphinée S, Exner G, Bostanci B, et al. Quality of life in patients with spinal cord injury-basic issues, assessment, and recommendations. Restor Neurol Neurosci 2002;20:135-49.

11. Tate D, Forchheimer M. Review of cross-cultural issues related to quality of life after spinal cord injury. Top Spinal Cord Inj Rehabil 2014;20:181-90.

12. Geyh S, Müller R, Peter C, et al. Capturing the psychologicpersonal perspective in spinal cord injury. Am J Phys Med Rehabil 2011;90:S79-S96.

13. Peter C, Müller R, Cieza A, et al. Psychological resources in spinal cord injury: a systematic literature review. Spinal Cord 2012;50:188-201.

14. Boakye M, Leigh BC, Skelly AC. Quality of life in persons with spinal cord injury: comparisons with other populations. J Neurosurg Spine 2012;17:29-37.

15. Geyh S, Ballert C, Sinnott A, et al. Quality of life after spinal cord injury: a comparison across six countries. Spinal Cord 2013;51:322-6.

16. Barker RN, Kendall MD, Amsters DI, et al. The relationship between quality of life and disability across the lifespan for people with spinal cord injury. Spinal Cord 2009;47:149-55.

17. Gill M. Psychosocial implications of spinal cord injury. Crit Care Nurs Q 1999;22:1-7.

18. Smith B, Sparkes AC, Men SAC. Men, sport, spinal cord injury, and narratives of hope. Soc Sci Med 2005;61:1095-105.

19. Sparkes A, Sport SB, Injury SC. Embodied Masculinities, and the Dilemmas of Narrative Identity. Men Masc 2002;4:258-85.

20. Mountjoy M, Junge A. The role of International Sport Federations in the protection of the athlete's health and promotion of sport for health of the general population. Br J Sports Med 2013;47:1023-7.

21. Bonanno GA, Kennedy P, Galatzer-Levy IR, et al. Trajectories of resilience, depression, and anxiety following spinal cord injury. Rehabil Psychol 2012;57:236-47.

22. The World Health Organization: The WHOQOL Group. Whogol-Bref: Introduction, Administration, Scoring and Generic Version of the Assessment, 1996.

23. Geyh S, Fellinghauer BA, Kirchberger I, et al. Cross-cultural validity of four quality of life scales in persons with spinal cord injury. Health Qual Life Outcomes 2010;8:94.

24. Hill MR, Noonan VK, Sakakibara BM, et al. Quality of life instruments and definitions in individuals with spinal cord injury: a systematic review. Spinal Cord 2010;48:438-50.

25. Jang $\mathrm{Y}$, Hsieh $\mathrm{CL}$, Wang $\mathrm{YH}$, et al. A validity study of the WHOQOLBREF assessment in persons with traumatic spinal cord injury. Arch Phys Med Rehabil 2004;85:1890-5.

26. Chang $\mathrm{FH}$, Wang $\mathrm{YH}$, Jang $\mathrm{Y}$, et al. Factors associated with quality of life among people with spinal cord injury: application of the International Classification of Functioning, Disability and Health model. Arch Phys Med Rehabil 2012;93:2264-70.

27. Bradshaw D, Steyn K. Poverty and Chronic Diseases in South Africa Technical report - MRC, 2001.

28. Fekete C, Eriks-Hoogland I, Baumberger M, et al. Development and validation of a self-report version of the Spinal Cord Independence Measure (SCIM III). Spinal Cord 2013;51:40-7.

29. Whiteneck GG. Issues affecting the selection of participation measurement in outcomes research and clinical trials. Arch Phys Med Rehabil 2010;91:S54-S59.

30. Brown M, Dijkers MP, Gordon WA, et al. Participation objective, participation subjective: a measure of participation combining outsider and insider perspectives. J Head Trauma Rehabil 2004;19:459-81 http://www.ncbi.nlm.nih.gov/pubmed/15602309.

31. Magasi SR, Heinemann AW, Whiteneck GG. Quality of Life/ Participation Committee. Participation following traumatic spinal cord injury: an evidence-based review for research. J Spinal Cord Med 2008;31:145-56.

32. Brown M. Participation: the insider's perspective. Arch Phys Med Rehabil 2010:91:S34-S37.
33. Eyssen IC, Steultjens MP, Dekker J, et al. A systematic review of instruments assessing participation: challenges in defining participation. Arch Phys Med Rehabil 2011;92:983-97.

34. Heinemann AW, Lai JS, Magasi S, et al. Measuring participation enfranchisement. Arch Phys Med Rehabil 2011;92:564-71.

35. Heinemann AW, Magasi S, Bode RK, et al. Measuring enfranchisement: importance of and control over participation by people with disabilities. Arch Phys Med Rehabil 2013;94:2157-65.

36. Wong AWK, Ng S, Dashner J, et al. Relationships between environmental factors and participation in adults with traumatic brain injury, stroke, and spinal cord injury: a cross-sectional multi-center study. Qual Life Res 2017:26:2633-45.

37. Field A. Discovering Statistics using IBM SPSS Statistics. 3rd Ed: Sage, 2009.

38. Graham L, Ross E. Disparities in Quality of Life Among South Africans With and Without Disabilities. Soc Indic Res 2016;127:721-39.

39. Skevington SM, Lotfy M, O'Connell KA. WHOQOL Group. The World Health Organization's WHOQOL-BREF quality of life assessment: psychometric properties and results of the international field trial. A report from the WHOQOL group. Qual Life Res 2004;13:299-310.

40. Boschen KA, Tonack M, Gargaro J. Long-term adjustment and community reintegration following spinal cord injury. Int $J$ Rehabil Res 2003;26:157-64.

41. Mitchell T, Barlow CE. Review of the role of exercise in improving quality of life in healthy individuals and in those with chronic diseases. Curr Sports Med Rep 2011;10:211-6.

42. Anneken V, Hanssen-Doose A, Hirschfeld S, et al. Influence of physical exercise on quality of life in individuals with spinal cord injury. Spinal Cord 2010;48:393-9.

43. Ginis K a M, Jorgensen S, Stapleton J. Exercise and Sport for Persons With Spinal Cord Injury. Phys Med Rehabil 2012;4:894-900.

44. Sahlin KB, Lexell J. Impact of Organized Sports on Activity, Participation, and Quality of Life in People With Neurologic Disabilities. Pm R 2015:7:1081-8.

45. Strachan SM, Woodgate J, Brawley LR, et al. The Relationship of Self-Efficacy and Self-Identity to Long-Term Maintenance of Vigorous Physical Activity1. J Appl Biobehav Res 2005;10:98-112.

46. Smith B. Sporting Spinal Cord Injuries, Social Relations, and Rehabilitation Narratives: An Ethnographic Creative Non-Fiction of Becoming Disabled through Sport. Sociol Sport J 2013;30:132-52.

47. Sparkes AC, Smith B. When narratives matter: men, sport, and spinal cord injury. Med Humanit 2005;31:81-8.

48. Hawkins C, Coffee P, Soundy A. Considering how athletic identity assists adjustment to spinal cord injury: a qualitative study. Physiotherapy 2014;100:268-74.

49. Perrier M-J, Sweet SN, Strachan SM, et al. I act, therefore I am: Athletic identity and the health action process approach predict sport participation among individuals with acquired physical disabilities. Psychol Sport Exerc 2012;13:713-20.

50. Jaarsma EA, Dijkstra PU, Geertzen JH, et al. Barriers to and facilitators of sports participation for people with physical disabilities: a systematic review. Scand J Med Sci Sports 2014;24:871-81.

51. Barclay L, McDonald R, Lentin P. Social and community participation following spinal cord injury: a critical review. Int $J$ Rehabil Res 2015;38:1-19.

52. Adriaansen JJ, Ruijs LE, van Koppenhagen CF, et al. Secondary health conditions and quality of life in persons living with spinal cord injury for at least ten years. J Rehabil Med 2016;48:853-60.

53. Noonan VK, Fallah N, Park SE, et al. Health care utilization in persons with traumatic spinal cord injury: the importance of multimorbidity and the impact on patient outcomes. Top Spinal Cord Inj Rehabil 2014;20:289-301.

54. Piatt JA, Nagata S, Zahl M, et al. Problematic secondary health conditions among adults with spinal cord injury and its impact on social participation and daily life. J Spinal Cord Med 2016;39:693-8.

55. Hastings BM, Ntsiea MV, Olorunju S. Factors that influence functional ability in individuals with spinal cord injury: A cross-sectional observational study. S Afr J Physiother 2015;71:1-7.

56. Joseph C, Scriba E, Wilson V, et al. People with Spinal Cord Injury in Republic of South Africa. Am J Phys Med Rehabil 2017:96:S109-S111.

57. Republic of South Africa, Department of Health. National Rehabilitation Policy, 2000.

58. Harris B, Goudge J, Ataguba JE, et al. Inequities in access to health care in South Africa. J Public Health Policy 2011;32 Suppl 1(Suppl 1):S102-S123.

59. Ataguba JE, Mclntyre D. Paying for and receiving benefits from health services in South Africa: is the health system equitable? Health Policy Plan 2012;27 Suppl 1:i35-i45. 
60. Hermanus FJ, Draper CE, Noakes TD. Spinal cord injuries in South African Rugby Union (1980 - 2007). S Afr Med J 2010;100:230-4.

61. Cao Y, Krause JS, Saunders LL, et al. Household income and subjective well-being after spinal cord injury: a longitudinal study. Top Spinal Cord Inj Rehabil 2014;20:40-7.

62. Øderud T. Surviving spinal cord injury in low income countries. Afr $J$ Disabil 2014;3:1-9.

63. Lidal IB, Huynh TK, Biering-Sørensen F. Return to work following spinal cord injury: a review. Disabil Rehabil 2007;29:1341-75.
64. Statistics South Africa. Profile of persons with disability in South Africa, 2014.

65. Donohue D, Bornman J. The challenges of realising inclusive education in South Africa. S Afr J Educ 2014;34:1-14.

66. Branson N, Leibbrandt M. Educational Attainment and Labour Market Outcomes in South Africa, 1994-2010. OECD Economics Department Working Papers 2013.

67. Calman KC. Quality of life in cancer patients--an hypothesis. J Med Ethics 1984;10:124-7. 